\title{
Respiratory tract infections in primary health care: prevalence and antibiotic prescribing in a primary care practice during one year
}

\author{
MAŁGORZATA PIETRZYKOWSKA ${ }^{\mathrm{A}-\mathrm{F}}$, KATARZYNA NOWICKA-SAUER ${ }^{\mathrm{D}-\mathrm{F}}$, JANUSZ SIEBERT ${ }^{\mathrm{A}, \mathrm{D}, \mathrm{G}}$ \\ ORCID ID: 0000-0003-3663-5393 \\ ORCID ID: 0000-0002-7510-5478 \\ ORCID ID: 0000-0002-7254-271X
}

Department of Family Medicine, Medical University of Gdansk, Poland

A - Study Design, B - Data Collection, C - Statistical Analysis, D - Data Interpretation, E - Manuscript Preparation, F - Literature Search, G - Funds Collection

Summary Background. Respiratory tract infections (RTIs) are one of the main reasons for primary health care (PHC) visits. In spite of the predominant viral aetiology of RTIs, antibiotherapy is common, especially in outpatient clinics.

Objectives. The aim was to analyse the prevalence of different RTIs and prescription of antibiotics in the adult population of an urban PHC practice in the north of Poland.

Material and methods. A retrospective analysis of the medical files of 1,735 visits of 1,354 patients with a diagnosis of RTI between January and December 2014 was carried out.

Results. The results include $1,112(64.1 \%)$ visits by females and 623 (35.9\%) visits by males. The mean age of patients was $49.5 \pm 19.8$ years of age. An unspecified infection was diagnosed in $59.7 \%$ of the visits and common cold in $13.6 \%$. Less than $1 \%$ of the annual visits took place in summer, $25.82 \%$ in December. Antibiotherapy was prescribed for $68 \%$ of patients. Azithromycin ( $25.2 \%)$, amoxicillin with clavulanic acid $(21.8 \%)$, amoxicillin $(19.5 \%)$ and cefuroxime $(10 \%)$ were the most commonly used for $76.5 \%$ of patients prescribed with antibiotics. From the penicillin group, only amoxicillin or amoxicillin with clavulanic acid were prescribed.

Conclusions. 1. More than half of RTIs were diagnosed as 'unspecified infection'. This indicates a need to improve the precision of the diagnostic process. 2. The huge seasonal variation in RTIs determines the need to optimize the PHC work system. 3. Notwithstanding the growing awareness of the dangers of antibiotic overuse, antibiotics were prescribed for $2 / 3$ of patients.

Key words: respiratory tract infections, anti-bacterial agents, primary health care.

Pietrzykowska M, Nowicka-Sauer K, Siebert J. Respiratory tract infections in primary health care: prevalence and antibiotic prescribing in a primary care practice during one year. Fam Med Prim Care Rev 2021; 23(2): 203-208, doi: https://doi.org/10.5114/ fmpcr.2021.105924.

\section{Background}

Respiratory tract infections (RTIs) are in the top ten of all reasons for patient visits to primary health care (PHC) [1-3]. They are not only the cause of $9-28 \%$ of all appointments, but also the most frequent among acute illnesses.

About $80 \%$ of all antibiotics are used in outpatient health care [4-6]. From $50 \%$ up to even $70 \%$ of all antibiotics prescribed in PHC are used for treating respiratory tract infections.

Despite the predominant viral etiology of RTIs [7, 8], antibiotherapy is common. It is believed that between $20 \%$ to $50 \%$ of antibiotics are prescribed contrary to guidelines [9]. Excessive antibiotherapy leads to the growing drug resistance of bacteria and, as a consequence, to adverse health, social and economic effects [10-12]. It seems important to identify the factors related to the high prescription rate of antibiotics observed, as this can contribute to planning preventive actions.

\section{Objectives}

The aim of the present study was to assess the frequency of diagnosis of a particular RTI in a chosen primary care practice in Poland, as well as to investigate the choice of particular antibi- otic groups. Additionally, the association between the type of $\mathrm{RTI}$ and the prescribed treatment was investigated.

\section{Material and methods}

The study was performed in a single primary care outpatient clinic in the Tri-city area in the Pomeranian Voivodeship in Poland in 2014 (from January $2^{\text {nd }}$ to December $31^{\text {st }}$ ). The medical records from the IT system of all 1,735 visits of 1,354 adult public sector patients with a diagnosis of acute respiratory tract infection (RTI) were retrospectively reviewed anonymously. A diagnosis of respiratory tract infection was established according to the $10^{\text {th }}$ revision of International Statistical Classification of Diseases and Related Health Problems (ICD-10).

Inclusion criteria: (i) 18 years of age and above confirmed by date of birth; (ii) diagnosis of acute RTI according to ICD-10 coded with the letter J. Exclusion criteria: (i) under 18 years of age; (ii) chronic respiratory tract infection (asthma or chronic obstructive pulmonary disease) marked by a primary care physician as the main purpose of the patient's visit; (iii) diagnosis of other infections not coded with the letter J (e.g. otitis media (ICD-10 code: H65-H67), pertussis (ICD-10 code: B37) and diphtheria (ICD-10 code: B36).

The study project was approved by the Independent Bioethics Commission for Research of the Medical University of Gdańsk. 


$\begin{aligned} & \text { Table 1. Characteristics of patients with RTls visiting the chosen } \\
& \text { primary health care practice }\end{aligned}$
\begin{tabular}{|l|l|} 
& $\begin{array}{l}\text { Analyzed visits } \\
n(\%) \\
n=1,735\end{array}$ \\
\hline $\begin{array}{l}\text { Gender } \\
\text { female } \\
\text { male }\end{array}$ & $1,112(64.1)$ \\
\hline Age & $623(35.9)$ \\
\hline mean (SD)* & $49.5(19.8)$ \\
range (min-max) & $18.0-100.0$ \\
median & 50.0 \\
$95 \% \mathrm{Cl}$ & {$[48.6-50.4]$} \\
\hline
\end{tabular}

* SD - standard deviation.

\section{Statistical analysis}

For statistical analysis, STATISTICA PL 12.0 (StatSoft Poland) was used. The normality of the distribution of variables was tested with the Shapiro-Wilk test. Quantitative variables are expressed as mean and standard deviation $( \pm S D)$ or median with min-max with $95 \%$ confidence interval $(95 \% \mathrm{Cl})$. Categorical variables were presented using number and proportions. Levene's (Brown-Forsythe) test was used to verify the hypothesis of equal variances. Student's $t$-Test and the $U$ Mann-Whitney tests were applied. Chi-square independence tests were used for categorical variables. In order to explore factors influencing antibiotic prescription, an analysis of univariate and multivariate regression was performed. The significance level was set at $p \leq 0.05$.

\section{Results}

The results include data from 1,735 visits: 1,112 (64.1\%) visits by females and $623(35.9 \%)$ visits by males. The mean age of patients was 49.5 ( $S D=19.8$ years; median 50 , range: $18-100$ years).

\section{Prevalence of RTIs}

The prevalence of RTIs according to ICD-10 is presented in Table 2. In the studied sample, the most prevalent diagnosis was acute upper respiratory infections of multiple and unspecified sites (J06) $-59.7 \%$. Acute nasopharyngitis (common cold) (J00) was diagnosed in $13.6 \%$ of the patients, and acute bronchitis
(J20) in $11.6 \%$. For the purpose of statistical analysis, all pneumonia diagnoses were combined (J15, J16 and J18). In total, pneumonia was diagnosed in 32 patients (1.9\%).

\begin{tabular}{|l|l|l|}
\hline \multicolumn{3}{|l|}{ Table 2. Prevalence of the diagnosis of RTIs according to ICD-10 } \\
\hline $\begin{array}{l}\text { ICD-10 } \\
\text { code }\end{array}$ & ICD-10 diagnosis & $\begin{array}{l}n=1,735 \\
n(\%)\end{array}$ \\
\hline J06 & $\begin{array}{l}\text { Acute upper respiratory infections of } \\
\text { multiple and unspecified sites }\end{array}$ & $1,035(59.7)$ \\
\hline J00 & Acute nasopharyngitis [common cold] & $236(13.6)$ \\
\hline J20 & Acute bronchitis & $201(11.6)$ \\
\hline J02 & Acute pharyngitis & $89(5.1)$ \\
\hline J01 & Acute sinusitis & $51(2.9)$ \\
\hline J03 & Acute tonsillitis & $47(2.7)$ \\
\hline J18 & Pneumonia, unspecified organism & $29(1.7)$ \\
\hline J04 & Acute laryngitis and tracheitis & $25(1.4)$ \\
\hline J22 & $\begin{array}{l}\text { Unspecified acute lower respiratory } \\
\text { infection }\end{array}$ & $13(0.7)$ \\
\hline J11 & $\begin{array}{l}\text { Influenza due to unidentified influenza } \\
\text { virus }\end{array}$ & $3(0.2)$ \\
\hline J39 & $\begin{array}{l}\text { Other diseases of upper respiratory } \\
\text { tract }\end{array}$ & $2(0.1)$ \\
\hline J16 & $\begin{array}{l}\text { Pneumonia due to other infectious } \\
\text { organisms, not elsewhere classified }\end{array}$ & $2(0.1)$ \\
\hline J15 & $\begin{array}{l}\text { Bacterial pneumonia, not elsewhere } \\
\text { classified }\end{array}$ & $1(0.1)$ \\
\hline J34 & $\begin{array}{l}\text { Other and unspecified disorders of nose } \\
\text { and nasal sinuses }\end{array}$ & $1(0.1)$ \\
\hline
\end{tabular}

The next step of analysis was to explore the seasonal prevalence of RTIs in the studied primary care practice. The results are presented in Figure 1. Respiratory tract infections showed a definite seasonality - the fewest patient visits due to RTIs took place during the summer months: June, July and August (less than $1 \%$ of the annual total of appointments), while most visits - $25.82 \%$ - in December.

The next step of the study was an analysis of antibiotic treatment, including frequency of antibiotherapy given and prescription of a particular antibiotic. Detailed results are presented in Table 3. As presented, antibiotic treatment was prescribed in $68 \%$ of patients' visits.

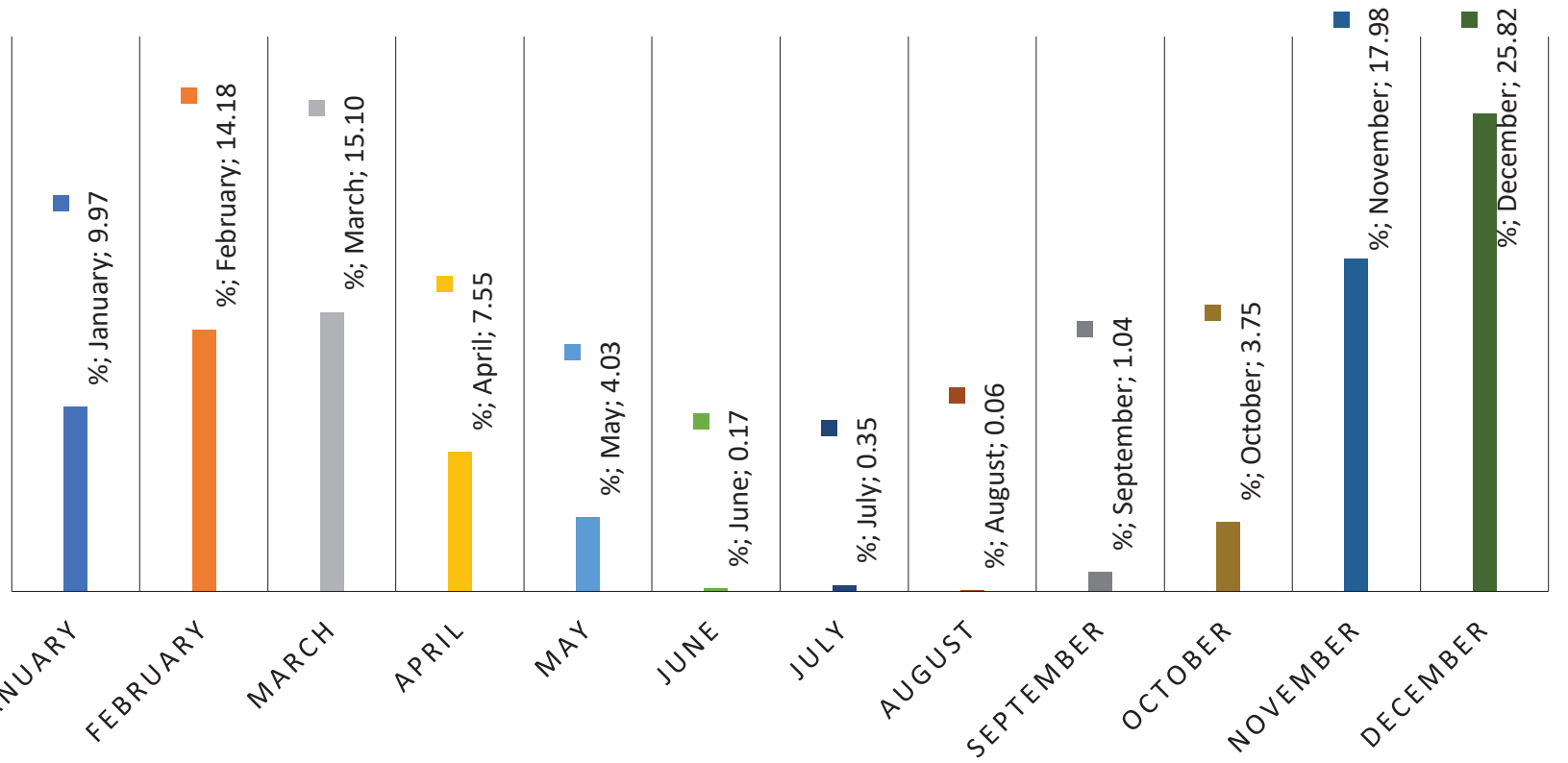

Figure 1. Prevalence of RTIs in relation to month of the year in the chosen primary care setting in 2014 (percentage of visits with RTIs) 


\begin{tabular}{|c|c|}
\hline & $\begin{array}{l}\text { Patients } \\
n(\%)\end{array}$ \\
\hline $\begin{array}{l}\text { Antimicrobial treatment } \\
\text { no } \\
\text { yes }\end{array}$ & $\begin{array}{l}554(32.0) \\
1,177(68.0)\end{array}$ \\
\hline $\begin{array}{l}\text { Prescribed antimicrobial } \\
\text { Azithromycin } \\
\text { Amoxicillin with clavulanic acid } \\
\text { Amoxicillin } \\
\text { Cefuroxime } \\
\text { Clarithromycin } \\
\text { Spiramycin } \\
\text { Doxycycline } \\
\text { Ciprofloxacin } \\
\text { Moxifloxacin } \\
\text { Clindamycin } \\
\text { Roxithromycin } \\
\text { Lincomycin } \\
\text { Sulfamethoxazole + trimethoprim }\end{array}$ & $\begin{array}{l}297(25.2) \\
257(21.8) \\
229(19.5) \\
118(10.0) \\
101(8.6) \\
62(5.3) \\
33(2.8) \\
29(2.5) \\
24(2.0) \\
19(1.6) \\
6(0.5) \\
1(0.1) \\
1(0.1)\end{array}$ \\
\hline
\end{tabular}

In the current study, we analyzed the frequency of prescription of antibiotics in a particular RTI classified in ICD-10. In the case of 4 patients, no data regarding treatment was available. Thus, 1,731 cases were analyzed. The results are presented in Table 4. Antibiotics were the most frequently prescribed in $\mathrm{J03}$ (acute tonsillitis) and J20 (acute bronchitis). One of three patients diagnosed with influenza (J11) was given antibiotics. Antibiotics were prescribed in $4.2 \%$ of patients with a J00 diagnosis.

\begin{tabular}{|l|l|l|}
\hline \multicolumn{3}{|l|}{ Table 4. Number and percentage of patients treated with anti- } \\
biotics according to ICD-10 diagnosis of RTI \\
\hline Diagnosis & $\begin{array}{l}\text { Number of patients } \\
\text { with a particular diag- } \\
\text { nosis* } \\
n=1731\end{array}$ & $\begin{array}{l}\text { Antibiotic prescription } \\
n(\%)\end{array}$ \\
\hline $\mathrm{J} 00$ & 236 & $10(4.2)$ \\
\hline $\mathrm{J} 01$ & 51 & $40(78.4)$ \\
\hline $\mathrm{J} 02$ & 89 & $64(71.9)$ \\
\hline $\mathrm{J} 03$ & 47 & $42(89.4)$ \\
\hline $\mathrm{J} 04$ & 25 & $18(72)$ \\
\hline $\mathrm{J} 06$ & 1,034 & $800(77.4)$ \\
\hline $\mathrm{J} 11$ & 3 & $1(33.3)$ \\
\hline $\mathrm{J} 20$ & 198 & $173(87.4)$ \\
\hline $\mathrm{J} 22$ & 13 & $9(69.2)$ \\
\hline $\mathrm{J} 34$ & 1 & $0(0.0)$ \\
\hline $\mathrm{J} 39$ & 2 & $1(50.0)$ \\
\hline $\mathrm{J} 15 / \mathrm{J} 16 / \mathrm{J} 18$ & 32 & $21(65.6)$ \\
\hline
\end{tabular}

$* 100 \%$ - number of patients with a particular diagnosis.

The comparison between groups of patients who received antibiotic treatment ('Antimicrobial prescribed') and those who did not receive this kind of treatment ('No antimicrobial prescribed') revealed several statistically significant differences. Detailed results are presented in Table 5. In the group of patients with a prescribed antibiotic, the percentage of patients with acute nasopharyngitis (common cold; J00) (0.9\% vs $40.8 \%$ without antibiotics; $p=0.0001$ ) was statistically significantly lower. The percentage of patients diagnosed with acute tonsillitis (J03) ( $3.6 \%$ vs $0.9 \%$ without antibiotics; $p=0.0015$ ), acute upper respiratory infections of multiple and unspecified sites (J06) (66.1\% vs $42.3 \%$ without antimicrobial treatment; $p=0.0001$ ) and acute bronchitis (J20) (14.5\% vs $4.7 \%$ with no antibiotics prescribed; $p=0.0001$ ) was statistically significantly higher.

\begin{tabular}{|c|c|c|c|}
\hline Diagnosis & $\begin{array}{l}\text { No antimicrobial } \\
\text { prescribed } \\
(n=554) \\
n(\%)\end{array}$ & $\begin{array}{l}\text { Antimicrobial } \\
\text { prescribed } \\
(n=1177) \\
n(\%)\end{array}$ & $p$ \\
\hline 100 & $226(40.8)$ & $10(0.9)$ & $0.0001^{*}$ \\
\hline $\mathrm{J} 01$ & $11(2.0)$ & $40(3.4)$ & 0.1060 \\
\hline $\mathrm{J} 02$ & $25(4.5)$ & $64(5.4)$ & 0.4206 \\
\hline $\mathrm{J} 03$ & $5(0.9)$ & $42(3.6)$ & $0.0015^{*}$ \\
\hline $\mathrm{J} 04$ & $7(1.3)$ & $18(1.5)$ & 0.6683 \\
\hline $\mathrm{J} 06$ & $235(42.3)$ & 779 (66.1) & $0.0001^{*}$ \\
\hline $\mathrm{J} 11$ & $2(0.4)$ & $1(0.1)$ & 0.1971 \\
\hline $\mathrm{J} 15$ & $1(0.2)$ & $0(0.0)$ & 0.1445 \\
\hline J16 & $1(0.2)$ & $1(0.1)$ & 0.5843 \\
\hline $\mathrm{J} 18$ & $9(1.6)$ & 20 (1.7) & 0.9135 \\
\hline $\mathrm{J} 20$ & $26(4.7)$ & $173(14.5)$ & $0.0001^{*}$ \\
\hline $\mathrm{J} 22$ & $4(0.7)$ & $9(0.8)$ & 0.9259 \\
\hline J34 & $1(0.2)$ & $0(0.0)$ & 0.1445 \\
\hline$J 39$ & $1(0.2)$ & $1(0.1)$ & 0.5843 \\
\hline J15/J16/J18 & $11(2.0)$ & $21(1.8)$ & 0.7682 \\
\hline
\end{tabular}

* Statistically significant differences, $p \leq 0.05$.

Among the 32 patients with a diagnosis of pneumonia (J15/ /J16/J18), 13 had received antibiotics prior to the current visit. 21 patients were given antibiotics during the analyzed visit. In 7 patients with pneumonia who did not take antibiotics and did not receive it, 4 patients were referred to hospital.

\section{Discussion}

\section{Summary}

In the current study, performed in a typical PHC in Poland, more than half of RTIs were diagnosed as 'unspecified infection'. Notwithstanding the growing awareness of the dangers of antibiotic overuse, antibiotics were prescribed for $2 / 3$ of adult patients diagnosed with an RTI. Widespread broad-spectrum antibiotics were mainly used. Azithromycin, amoxicillin with clavulanic acid, amoxicillin and cefuroxime were prescribed for a total of $76.5 \%$ patients treated with antibiotics, regardless of national guidelines [13]. It should be stressed that despite the diagnoses of tonsillitis, no phenoxymethylpenicillin (Penicillin V) was used. Diagnosis of a 'common cold' was related to a lower rate of antibiotic prescription. The results suggest that the type of diagnosis determined the chosen treatment option. Additionally, the study indicated a huge seasonal variation in RTIs.

\section{Strengths and limitations}

The main strength of the current research is the fact that the study was based on 'real world' data from a single primary care setting. The analysis of all patients' visits attending the primary care office in 2014 (January to December) with a respiratory tract infection also enabled us to trace the fluctuation of appointments. The retrospective analysis of files included in the health information system eliminated any possible bias related to the physicians' awareness of the study aim, which might have influenced their diagnostic and treatment decisions.

The study also has its limitations. The analysis of associations between currently diagnosed infections and chronic and/ /or coexisting diseases, biometric data and addictions was not possible, since this data was not included in the system files. The current analysis was performed in a single primary care setting and did not involve patients below 18 years of age. In the 
present study, symptomatic treatment was not analyzed, since its main aim was to assess the prevalence of antibiotic prescription, as well as type of prescribed antibiotic.

Due to the different methodology used in other studies (analysis during a period of higher morbidity of RTIs, i.e. autumn/winter) [14-21], randomly chosen patients [17], questionnaires with pre-determined diagnoses [18] or electronic data [19-22] or use of a different classification - ICD-10 or the International Classification of Primary Care (ICPC), a direct comparison of the results obtained was not possible. However, some main observations should be emphasized.

The results of the current study suggest that the recognition of RTIs is very vague. The most common diagnosis in our study was "acute upper respiratory infections of multiple and unspecified sites - URTIs - J06 in ICD-10. The prevalence of this type of diagnosis reached nearly $60 \%$ of all respiratory tract infections, while in other countries, these rates are much lower - from about $19 \%$ in Norway [14] and UK [23] to extremely low $-0.25 \%$ in Hong Kong [22] (code R74 -'acute upper respiratory tract infection' in the ICPC classification). The literature review revealed that 'upper respiratory tract infections, unspecified' is generally one of the most common diagnoses. Wändell et al. revealed that $\mathrm{J} 06$ was the most common disease diagnosed in primary care [24]. Moreover, a systematic review of studies published between 1996 and 2016 concerning data from PHC settings in 12 countries ( 5 continents) confirmed that URTIs were the most frequent reported condition [25].

Panasiuk et al. [17], after analyzing the records of randomly selected patients with acute RTIs, observed that the most common diagnoses were acute pharyngitis and tonsillitis (J02 and J03) $-33.5 \%$, acute upper respiratory tract infection of multiple or unspecified sites (J06) $-30.2 \%$, and 'common cold' (J00) $18.8 \%$. These are similar to other studies, where the acute pharyngitis and tonsillitis are a common cause of PHC visits, in some countries reaching approximately 200 consultation per 1,000 people annually $[26,27]$. In the Spanish part of the Happy Audit, the most common were 'common cold' $(40.2 \%)$, pharyngitis (15.1\%) and acute bronchitis (11.8\%) [28].

In the current study, $68 \%(1,179)$ of visits concluded with an antibiotic prescription.

A high antibiotic prescription rate (from 61\% [16] to even $82 \%$ [29] in the rural PHC) due to respiratory tract infections was also observed by other Polish authors. Data from the USA shows that only half of antibiotic prescriptions due to acute RTIs were estimated to be ordered properly [30].

Analysis of the antibiotic prescribing patterns performed by the National Ambulatory Medical Care Survey (NAMCS) in 2007-2009 showed that PHC physicians overused antibiotics. In $50 \%$ of cases diagnosed later as 'non-antibiotic appropriate acute respiratory infection' (upper respiratory infection, nonstreptococcal pharyngitis and laryngitis, bronchitis), these medications were prescribed [31].

The Happy Audit study revealed that in 2008 in Denmark, $70 \%$ to $75 \%$ of visits with a diagnosis of upper respiratory tract infection concluded with an antibiotic prescription by family doctors. In the same study, $90 \%$ of patients with pneumonia were ordered antibiotics. The Netherlands is one of the countries with the lowest antibiotic prescription rates [32]; nonetheless, according to Cals et al. [33], nearly a quarter of a million antibiotics are prescribed unnecessary annually.

In the current study, in the case of more than $70 \%$ of 'upper RTIs unspecified', antibiotics were ordered. The prescription rate in the diagnosis of upper respiratory tract infections varied from $16 \%$ in Norway [14] to $47 \%$ in the United Kingdom [21], while Kung et al. observed $1.9 \%$ in Hong Kong [22]. The prescription rate in bronchitis varied in different countries - in the Happy Audit [18] study, 37.7\% (Sweden), 93.2\% (Lithuania), $55 \%$ (Norway) and $83 \%$ (UK) of PHC doctors decided upon treatmentwith antibiotics.

In the European Union (EU), overall antibacterial consump- tion in the primary care sector varies, although in the last five years, no statistically significant change has been observed. According to the European Centre for Disease Prevention and Control (ECDC), in 2016, the average usage was 21.9 defined daily dose (DDD) [34] per 1,000 inhabitants per day, ranging from 10.4 in the Netherlands to 6.3 in Greece. In 2016, in Greece and Spain, a statistically significant increasing trend for overall antibacterial consumption was observed, while in Finland, Luxembourg, Norway and Sweden, the usage was decreasing [35]. In Poland, mean consumption of antibiotics outside hospitals is higher than the mean European consumption. In 2016, it was 22.8 DDD, while the peak in 2015-26.2 DDD per 1,000 inhabitants per day [29].

The unreasonable overuse of antibiotic in PHC settings has led to an escalation of bacterial resistance [21,30]. All over the world, scientists and financiers are trying to balance the questions of 'when and what to use'. Proper and precise diagnosis is the key to adequate treatment. It also seems that a general, vague diagnosis can contribute to unnecessary antibiotic use.

It is worth mentioning that recommendations for antibiotic use vary slightly between countries due to specific population conditions, especially antimicrobial resistance and drug accessibility, but, in general all over the word, the critical importance of 'rational antibiotic use' is emphasized [9, 10, 36, 37].

\section{Implications for research and/or practice}

The studies show that despite regularly updated recommendations, the primary care professionals still excessively prescribe antibiotics [38, 39]. Only multifaceted interventions aiming at reducing overuse of antibiotics have been found to be effective and are better than single initiatives [12]. Studies revealed that only a strict national policy [10, 40], patients' and doctors' education $[41,42]$ and national health programs $[43$, 44] with wide and easy access to diagnostics tools [45, 46] can reduce antibiotic use.

One of the important factors that should be emphasized is also the workload of PHC doctors, which has significantly increased all over the world [47]. The lack of time for proper education and the need for 'efficient' time management can be some of the factors why physicians prescribe antibiotics [43, 48]. Thus, the help of a qualified medical assistant seems particularly desirable, especially during autumn and winter.

Moreover, access to a central database of patients' history (prescribed medication, comorbidity, coexisting chronic diseases) seems to be of great importance, as this may reduce adverse effects of polypharmacy and duplicate treatment. Such a central system may contribute to safe, effective and proper complex treatment, decreasing the risk of adverse events, sick leave and disability.

A literature review also revealed that Point-Of-Care Tests (POCT) can be a useful tool for both physicians and patients: (i) they are quick and relatively cost-effective; (ii) they facilitate a proper diagnosis [5, 49]; (iii) they can be helpful in convincing and assuring the patients on the viral origin of the infection and lack of necessity of antibiotic use [50].

\section{Conclusions}

RTIs are the most common cause of appointments in general practice. Recognizing more than half of RTIs as an 'unspecified infection' indicates the need to improve the precision of the diagnostic process. The huge seasonal variation in RTIs determines the need to optimize the PHC work system on an annual basis. Notwithstanding the growing awareness of the dangers of antibiotic overuse, antibiotics were prescribed for $2 / 3$ of adult patients diagnosed with an RTI. Azithromycin, amoxicillin with clavulanic acid, amoxicillin and cefuroxime were prescribed for a total of $76.7 \%$ patients treated with antibiotics. Such widespread broad-spectrum antibiotic use is not consistent with the 'guidelines for the management of respiratory tract infections 
in outpatient care'. No phenoxymethylpenicillin (Penicillin V) was used. One of the reasons for the frequent prescription of antibiotics is diagnostic uncertainty. This can be minimized by providing standard access to POCT and/or a round-the-clock laboratory. Further research on factors influencing antibiotic prescription seems vital.

Source of funding: This work was funded by the Medical University of Gdansk (ST-72).

Conflicts of interest: The authors declare no conflicts of interest.

\section{References}

1. Rui P, Okeyode T. National Ambulatory Medical Care Survey: 2015 State and National Summary Tables. Available from URL: http:// www.cdc.gov/nchs/ahcd/ahcd_products.htm.

2. Hryniewicz W. Alexander Project -5 years in Poland. Pol Merkur Lek 2003; 14(79): 5-8.

3. Bujnowska-Fedak MM, Sapilak BJ, Steciwko A. Epidemiologia schorzeń i struktura zachorowań w praktyce lekarza rodzinnego. Fam Med Prim Care Rev 2011; 13(2): 135-139.

4. Mölstad S, Lundborg CS, Karlsson A-K, et al. Antibiotic prescription rates vary markedly between 13 European Countries. Scand J Infect Dis 2002; 34 (5): 366-371.

5. Bjerrum L, Munck A, Reutskiy A, et al. Respiratory tract infections in general practice. Total results 2008/2009 from 6 countries and 618/511 GP's. 2010 (cited 20.10.2019). Available from URL: www.apo-danmark.dk/files/pub/3698.pdf .

6. Akkerman $\mathrm{AE}$, Wouden JC van der, Kuyvenhoven MM, et al. Antibiotic prescribing for respiratory tract infections in Dutch primary care in relation to patient age and clinical entities. J Antimicrob Chemother 2004; 54(6): 1116-1121.

7. Dzierżanowska D. Antybiotykoterapia praktyczna. Bielsko-Biała: $\alpha$-Medica Press; 2009.

8. Goossens H, Ferech M, Vander Stichele R, et al. Outpatient antibiotic use in Europe and association with resistance: a cross-national database study. Lancet 2005; 365(9459): 579-587.

9. Wise R, Hart T, Cars O, et al. Antimicrobial resistance. Is a major threat to public health. BMJ 1998; 317(7159): 609-610.

10. Hellman J, Aspevall O, Bengtsson B, et al. SWEDRES-SVARM 2014 2. A report on Swedish Antibiotic Utilisation and Resistance in Human Medicine (Swedres) and Swedish Veterinary Antibiotic Resistance Monitoring (Svarm) 2014. (cited 7.10.2019). Available from URL: https://www.folkhalsomyndigheten.se/contentassets/7bb3429f570c4ca0aa5dad4be3c1b58b/swedres-svarm-2014-14027.pdf.

11. Costelloe C, Metcalfe C, Lovering A, et al. Effect of antibiotic prescribing in primary care on antimicrobial resistance in individual patients: systematic review and meta-analysis. BMJ 2010; 340: c2096.

12. Llor C, Bjerrum L. Antimicrobial resistance: risk associated with antibiotic overuse and initiatives to reduce the problem. Ther Adv Drug Saf 2014; 5(6): 229-241.

13. Radzikowski PA. Rekomendacje postępowania w pozaszpitalnych zakażeniach układu oddechowego. Wyd. II. Warszawa: Narodowy Instytut Leków; 2016 (cited 7.01.2019). Available from URL: http://antybiotyki.edu.pl/pdf/Rekomendacje2016.pdf (in Polish).

14. Gjelstad S, Dalen I, Lindbaek M. GPs' antibiotic prescription patterns for respiratory tract infections - still room for improvement. Scand J Prim Health Care 2009; 27(4): 208-215.

15. Bjerrum L, Munck A, Gahrn-Hansen B, et al. Health Alliance for prudent antibiotic prescribing in patients with respiratory tract infections (HAPPY AUDIT) - impact of a non-randomised multifaceted intervention programme. BMC Fam Pract 2011; 12: 52, doi: 10.1186/1471-2296-12-52.

16. Chlabicz S, Ołtarzewska AM, Pytel-Krolczuk B. Respiratory tract infections: diagnosis and use of antibiotics by family physicians in northeastern Poland. Int J Antimicrob Agents 2004; 23(5): 446-450.

17. Panasiuk L, Lukas W, Paprzycki P, et al. Antibiotics in the treatment of upper respiratory tract infections in Poland. Is there any improvement? J Clin Pharm Ther 2010; 35(6): 665-669.

18. Bjerrum L, Munck A, Gahrn-Hansen B, et al. Health Alliance for Prudent prescribing, yield and use of antimicrobial drugs in the treatment of respiratory tract infections (happy audit). BMC Fam Pract 2010; 11: 29, doi 10.1186/1471-2296-11-29.

19. Andre M, Odenholt I, Schwan A, et al. Upper respiratory tract infections in general practice: diagnosis, antibiotic prescribing, duration of symptoms and use of diagnostic tests. Scand J Infect Dis 2002; 34(12): 880-886.

20. Ashworth $M$, Latinovic $R$, Charlton J, et al. Why has antibiotic prescribing for respiratory illness declined in primary care? A longitudinal study using the General Practice Research Database. J Public Health 2004; 26(3): 268-274.

21. Gonzales R, Malone DC, Maselli JH, et al. Excessive antibiotic use for acute respiratory infections in the United States. Clin Infect Dis 2001; 33(6): 757-762.

22. Kung K, Wong CKM, Wong SYS, et al. Patient presentation and physician management of upper respiratory tract infections: a retrospective review of over 5 million primary clinic consultations in Hong Kong. BMC Fam Pract 2014; 15: 95.

23. Gulliford MC, Dregan A, Moore MV, et al. Continued high rates of antibiotic prescribing to adults with respiratory tract infection: survey of 568 UK general practices. BMJ Open 2014; 4(10): e006245.

24. Wändell P, Carlsson AC, Wettermark B, et al. Most common diseases diagnosed in primary care in Stockholm, Sweden, in 2011. Fam Pract 2013; 30(5): 506-513.

25. Finley CR, Chan DS, Garrison S, et al. What are the most common conditions in primary care? Systematic review. Can Fam Physician 2018; 64(11): 832-840.

26. Armstrong GL, Pinner RW. Outpatient visits for infectious diseases in the United States, 1980 through 1996. Arch Intern Med 1999; 159(21): 2531-2536.

27. Hsiao C-J, Cherry DK, Beatty PC, et al. National Ambulatory Medical Care Survey: 2007 summary. Nat Health Stat Report 2010; 6(26): 1-32.

28. Llor C, Cots JM, Hernandez S, et al. Effectiveness of two types of intervention on antibiotic prescribing in respiratory tract infections in Primary Care in Spain. Happy Audit Study. Aten Primaria 2014; 46(9): 492-500.

29. Panasiuk L, Lukas W, Paprzycki P. Empirical first-line antibiotic therapy in adult rural patients with acute respiratory tract infections. Ann Agric Environ Med 2007; 14(2): 305-311.

30. Fleming-Dutra KE, Hersh AL, Shapiro DJ, et al. Prevalence of inappropriate antibiotic prescriptions among US ambulatory care visits, 2010-2011. JAMA 2016; 315(17): 1864-1873.

31. Mehrotra A, Gidengil CA, Setodji CM, et al. Antibiotic prescribing for respiratory infections. Am J Manag Care 2015; 21(4): 294-302.

32. Adriaenssens N, Coenen S, Versporten A, et al. European Surveillance of Antimicrobial Consumption (ESVAC): quality appraisal of antibiotic use in Europe. J Antimicrob Chemother 2011; 66: vi71-vi77.

33. Cals JWL, Butler CC, Hopstaken RM, et al. Effect of point of care testing for $\mathrm{C}$ reactive protein and training in communication skills on antibiotic use in lower respiratory tract infections: cluster randomised trial. BMJ 2009; 338: b1374. 
34. WHO Collaborating Centre for Drug Statistics Methodology. WHOCC-ATC/DDD Index. (cited 8.06.2018). Available from URL: https:// www.whocc.no/atc_ddd_index/?code = J.

35. Health Protection Surveillance Centre. Annual Epidemiological Report 2014-2018 (cited 20.10.2019). Available from URL: https:// www.hpsc.ie/abouthpsc/annualreports/.

36. WHO. WHO highlights the critical importance of 'rational antibiotic use'. 2011 (cited 27.06.2019). Available from URL: http://www. who.int/rhem/didyouknow/essential_medicines/rational_antibiotic_use/en/.

37. Cars O, Mölstad S, Melander A. Variation in antibiotic use in the European Union 2001. Lancet 2001; 357(9271): $1851-1853$.

38. Coenen S, Ferech M, Haaijer-Ruskamp FM, et al. European Surveillance of Antimicrobial Consumption (ESAC): quality indicators for outpatient antibiotic use in Europe. Qual Saf Health Care 2007; 16(6): 440-445.

39. Zoorob R, Sidani M, Fremont RD, et al. Antibiotic use in acute upper respiratory tract infections. Am Fam Physician 2012; 86(9): 817-822.

40. Rún Sigurđardóttir N, Nielsen ABS, Munck A, et al. Appropriateness of antibiotic prescribing for upper respiratory tract infections in general practice: comparison between Denmark and Iceland. Scand J Prim Health Care 2015; 33(4): 269-274.

41. Butler CC, Simpson SA, Dunstan F, et al. Effectiveness of multifaceted educational programme to reduce antibiotic dispensing in primary care: practice based randomised controlled trial. BMJ 2012; 344: d8173.

42. Arnold SR, Straus SE. Interventions to improve antibiotic prescribing practices in ambulatory care. Cochrane Database Syst Rev 2005; 4: 1-78.

43. Wrigley T, Manor C. Age and sex specific antibiotic prescribing patterns in General Practice in England and Wales, 1994 to 1998. Heal Stat Q 2002; 14: 735-736.

44. Yebyo H, Medhanyie AA, Spigt M, et al. C-reactive protein point-of-care testing and antibiotic prescribing for acute respiratory tract infections in rural primary health centres of North Ethiopia: a cross-sectional study. NPJ Prim Care Respir Med 2016; 26: 15076, doi: 10.1038/npjpcrm.2015.76.

45. Cals JWL, Chappin FHF, Hopstaken RM, et al. C-reactive protein point-of-care testing for lower respiratory tract infections: a qualitative evaluation of experiences by GPs. Fam Pract 2010; 27(2): 212-218.

46. Jakobsen KA, Melbye H, Kelly MJ, et al. Influence of CRP testing and clinical findings on antibiotic prescribing in adults presenting with acute cough in primary care. Scand J Prim Health Care 2010; 28(4): 229-236.

47. Fisher RF, Croxson $\mathrm{CH}$, Ashdown $\mathrm{HF}$, et al. GP views on strategies to cope with increasing workload: a qualitative interview study. $\mathrm{Br}$ J Gen Pract 2017; 67(655): e148-e156.

48. Nadeem Ahmed M, Muyot MM, Begum S, et al. Antibiotic prescription pattern for viral respiratory illness in emergency room and ambulatory care settings. Clin Pediatr (Phila) 2010; 49(6): 542-547.

49. Llor C, Bjerrum L, Arranz J, et al. C-reactive protein testing in patients with acute rhinosinusitis leads to a reduction in antibiotic use. Fam Pract 2012; 29(6): 653-658.

50. Stanton N, Francis NA, Butler CC. Reducing uncertainty in managing respiratory tract infections in primary care. Br J Gen Pract 2010; 60(581): e466-e475.

Tables: 5

Figures: 1

References: 50

Received: 25.05.2020

Reviewed: 20.06.2020

Accepted: 20.01.2021

Address for correspondence:

Małgorzata Pietrzykowska, MD, PhD

Katedra Medycyny Rodzinnej

ul. Dębinki 2

80-211 Gdańsk

Polska

Tel.: +48 58 349-15-75

E-mail: malpiet@gumed.edu.pl 